\title{
Lessons for human survival in a world without ecological templates: what can we learn from small-scale societies?
}

\author{
Roope O. Kaaronen $^{1,2,3}$, Mikael A. Manninen ${ }^{1,3}$ Emery Roe $^{4,5}$, Janne I. Hukkinen $^{2,3,4}$ and Jussi T. Eronen $^{1,3,6}$
}

\begin{abstract}
Historical records are incomplete templates for preparing for an uncertain future. The global utility of past ecological knowledge for present/future purposes is questioned as we move from Holocene to Anthropocene. To increase the adaptive capacity of today's societies, generalizable strategies must be identified for coping with uncertainty over a wide range of conditions and contingencies. We identify two key principles that increase adaptive capacities: diversification and precautionary heuristics. These sharply contrast with the present global state represented by the global production ecosystem characterized by: (1) homogenization and simplification of cultural practices and resource bases; (2) increased global connectivity and forced dissolution of cultural borders; and (3) centralization and intensification of modes of resource production and extraction. We highlight that responses of smaller-scale societies to risks and uncertainties are in many cases emulated by professionals in the high reliability management in today's critical infrastructures. This provides a modern template for managing unpredictability in the Anthropocene.
\end{abstract}

Key Words: adaptation; Anthropocene; climate change; cultural evolution; diversification; environmental change; high reliability management; precautionary principle; risk

\section{INTRODUCTION}

As the world steps out of the Holocene, the applicability and utility of historical templates as guides for what can be done now and ahead is much attenuated. Climate change, overexploitation of natural resources, as well as increasing globalization and urbanization are irreversibly altering landscapes to a degree that no contemporary ecosystems remain untouched by human activity (Barnosky et al. 2011, Dirzo et al. 2014, Barnosky and Hadly 2015, Ordonez and Svenning 2016, Järvensivu et al. 2018). Research reveals how humanity has emerged as a global force that is transforming the ecology of the entire planet (Ellis 2016, Stephens et al. 2019). The World is changing in ways that render historical templates all but obsolete when rethinking the future (Barnosky et al. 2017).

By "template," we mean each epoch's record of traditional socialecological knowledge or management strategies. Owing to ongoing climatic and ecological perturbations, we argue that such templates no longer provide reliable foundations or imitable analogies when preparing for future social-ecological challenges (see also Brewer and Riede 2018). It would be dangerous to rely on copying past practices to adapt to the uncertain future ahead. However, this does not mean nothing is to be learned from the past when preparing for present and future adaptation. The challenge that remains is to understand why and where past adaptive strategies have worked and what are the generalizable principles underlying their successes for going forward. By drawing on a diverse literature that documents and conceptualizes numerous mechanisms employed by small-scale and local communities to cope with and adapt to novel and changing environments, we uncovered some basic and generalizable principles for human adaptation. Finally, by drawing on lessons from contemporary high reliability management, we suggest how these principles could increase the capacities of societies today to cope and adapt in the unknown future.

The global human population currently uses resources extensively and unsustainably (Bringezu et al. 2017). We use roughly $40 \%$ of the net primary productivity (Foley et al. 2011) and have modified ecosystems to an untenable degree (Rist et al. 2014). This has led some researchers to describe the current predicament as the global production ecosystem (GPE). Features of the GPE include continued conversion of the Earth's biosphere into simplified production ecosystems, increased intensification, and expanding connectivity through the globalization of markets (Nyström et al. 2019). These are leading to breakdowns of social and ecological boundaries and tighter couplings across the ones that remain, as well as to the homogenization of fauna and flora, habitat simplification, and disruption of natural feedback systems.

Another important process underway is the re-evaluation of history and our place in it. First, the long path of human technological advancement that served to free us from many constraining limitations has started to backfire with ever increasing perturbations. Technological and organizational complexification is demanding increasing amounts of energy and resources: today, societies use half of their material production to upkeep the existing material stocks (Krausmann et al. 2017). Meanwhile, we are experiencing diminishing marginal returns on investment (in, e.g., innovation, agriculture, and health; Tainter 1988, 2006, Strumsky et al. 2010) and are creating new socialecological problems in the process (Chakrabarty 2009, Antal and Hukkinen 2010, Díaz et al. 2019). This creates both friction in human systems as well as uncertainty, owing also to the combinatorial explosion of unpredictable first- and second-order effects of new technologies and interventions. These dramatic

${ }^{1}$ PAES, Ecosystems and Environment Research Programme, Faculty of Biological and Environmental Sciences, University of Helsinki,

${ }^{2}$ Environmental Policy Research Group, University of Helsinki, ${ }^{3}$ Helsinki Institute of Sustainability Science (HELSUS), University of Helsinki, ${ }^{4}$ Faculty of Social Sciences, University of Helsinki, ${ }^{5}$ Center for Catastrophic Risk Management, University of California, Berkeley, ${ }^{6} \mathrm{BIOS}$ Research Unit, Helsinki, Finland 
changes and their consequences are at the heart of the Anthropocene debate (Emmett and Lekan 2016, Toivanen et al. 2017).

Second, the speed and extent of human modification of ecosystems and climate push us out of the Holocene envelope (Schellnhuber et al. 2016, Hansen et al. 2017) and past planetary boundaries (Steffen et al. 2015). According to an estimate by Hansen et al. (2017), we left the Holocene temperature variability in 1985, whereas Marcott et al. (2013) estimated that the World is on the verge of exceeding Holocene temperature conditions. The unfortunate truth is that the direct lessons we can learn from the past to adapt to the new are becoming increasingly limited when the conditions in the future drastically differ from what they are now or have been during the last 11,000 years (Williams and Jackson 2007, Ordonez and Svenning 2016), the period during which most of the complex human culture and all of the urban settlements have emerged (Woolf 2020). This is particularly the case when ecosystemic or climatic tipping points are breached, triggering nonlinear and unpredictable changes, if not ruptures, in human and nonhuman life support systems (Barnosky et al. 2012, Barnosky and Hadly 2015). Accordingly, it becomes all the more crucial to identify the limited lessons that can be learned from history.

Although the Anthropocene breaks with the Holocene, Holocene societies have themselves used a variety of responses to variability in ecosystems and climate (Halstead and O'Shea 1989, Schwartz and Nichols 2010, Faulseit 2016). This spatial and temporal distribution of responses provides a platform of practices, skills, and processes from which more appropriate templates are to evolve for wider investigation and application during the Anthropocene. Identifying the underlying generalizable features of these responses is paramount when preparing for the future. Using the historical record, we need to detect patterns and principles that are useful in the unpredictable future while sorting them out from the vast pool of templates tied to time and place.

Our argument is this: the lessons from past and present smallerscale communities offer approaches that enable localized and variable responses to the global changes underway. To uncover these lessons, we must engage in second-order learning (Bateson 2000), asking: what made these responses successful, and what are the general features underlying their success? We see clear similarities between the challenges of human-environment relationships for societies through time, and the demands that the social-ecological disruptions pose for critical infrastructures in industrial societies at present.

\section{PRINCIPLES FOR INCREASING ADAPTIVE \\ CAPACITIES}

We identified generalizable principles for adaptive capacities from the past to guide adaptation for the Anthropocene. By "adaptive capacities," we refer to the proactive or preventive measures that societies employ to anticipate future risks or uncertainties and adapt livelihoods accordingly (Keck and Sakdapolrak 2013). By "principles," in turn, we mean those generalizable features that underlie the function of specific adaptive capacities, i.e., the reasons why they work.

We highlighted two key principles used by small-scale and local communities that have increased their adaptive capacity to deal with changing environments and ecological conditions in the past: (1) diversification on multiple scales, and (2) evolving precautionary heuristics. We discuss how they have applied when dealing with uncertainty in the past, how they apply when adapting to the Anthropocene's climate and ecological crises, and follow-up on how modern high reliability management already emulates these key features of small-scale societies to deal with uncertain and variable systems.

We focused on these two principles because we perceived them to be relevant to present and future challenges, as well as applicable at multiple scales of societal evolution, ranging from individual and group behavior to institutions, large scale technologies, and societies. We also note that they have clear analogies in contemporary high reliability management, a research field with strong ties to practical solutions. We acknowledge that this is but a starting point for a broader discussion on uncovering more lessons from past adaptive capacities, particularly from the archaeological literature (Halstead and O'Shea 2004, Tainter 2006, Costanza et al. 2007, McAnany and Yoffee 2009, Schwartz and Nichols 2010, Faulseit 2016).

\section{Multi-level diversification}

Diversification exists in multiple forms, of which we focus on two: (1) diversity of societies or cultures (diversity between populations or communities), and (2) societal or cultural diversity (diversity within populations or communities). Because socio-cultural evolution follows a similar logic as Darwinian evolution (Mesoudi 2011, Henrich 2016, Laland 2018, Wilson 2020), diversification (variation) is a prerequisite for the evolution of societies and their adaptation to novel environments. First, cultural and behavioral traits of human populations are variable. Second, traits have uneven value when individuals or populations adapt to or compete in their societal or ecological niche. Third, successful traits are passed on through cultural transmission. Diversification in varying nested levels, between or within populations, functions to increase the adaptive capacity of socio-cultural units. Note that what we describe here is different from ideas typically described as "social Darwinism," because it is an increased variation/ diversity that increases adaptive capacity, not the culling of diversity (in the name of "selection for fitness") imagined by some social Darwinists (see Wilson 2020 for similar arguments).

Owing to these general underpinnings, diversification has been key to adaptation and buffering against environmental variability throughout human history (Halstead and O'Shea 1989). We argue that another factor explaining the success of diversification as an adaptive capacity is its relation to the law of requisite variety, also known as Ashby's law (Ashby 1960). To deal with an uncertain future, human societies require the maintenance of "requisite variety" in social and cultural systems: a repertoire of responses and strategies that are at least as nuanced as the problems societies and cultures might seek to control (Ashby 1960, Conant and Ashby 1970, Weick 1995).

\section{Between-group variation}

The diversification of human societies is a product of both species-specific cognitive capacities and demographic/ecological conditions over the past 100,000 years (Foley and Mirazón Lahr 2011). The processes through which societies generate variation in behavioral traits with high between-group differences has underpinned the success of our species (Foley and Mirazón Lahr 
2011, Henrich 2016). Although studies in socio-cultural evolution illustrate how evolution is not just ecologically determined, i.e., "societies living in the same environment can have entirely different behavioral practices" (Mesoudi 2011:12-13), the distribution of human population and communities is far from random. Human behavior continues to be strongly influenced by environmental factors, such as latitude, temperature, and rainfall (Foley and Mirazón Lahr 2011, Kelly 2013, Barsbai et al. 2021, Hill and Boyd 2021).

This between-group diversification has contributed to the spread of varied human societies into innumerable ecological niches. A key process in diversification is social learning (van Schaik and Burkart 2011, Hoppitt and Laland 2013, Mathew and Perreault 2015, Laland 2018). By transmitting information and behavioral traits socially, as well as by developing norms and traditions that facilitate these processes, humans have been spared much of the individual effort of trial and error. This evolution by social learning, a process that ultimately distinguishes one group from another, also allows communities to adapt to changing environments more rapidly than genetic evolution alone would allow (Boyd et al. 2011, Perreault 2012). How the mechanism of cultural diversification (through fission) works is not fully settled, and various explanations have been put forward, such as "the formation of boundaries between groups is promoted by resource reliability," or "reduced where variability and associated risk is such that it pays to maintain relationships across communities" (Foley and Mirazón Lahr 2011:1085), or that diversification mainly occurs when economic opportunity meets geographical isolation (Prentiss and Chatters 2003).

\section{Within-group variation}

Socio-cultural diversity within a population also enhances adaptive capacities of social units. In particular, diversification in the form of practices employed in anticipation of bad times, i.e., widely known in the don't put all your eggs in the same basket rule, has gathered attention within the field of economics (Halstead and O'Shea 2004). These and like practices feature especially as resilience strategies in response to destabilizing events in the global market (OECD and WTO 2019, Caselli et al. 2020) and in sustainable agricultural practices, in which diversification of crops and farming systems is regarded as key to sustainable and secure development of food production (Ellis 2000, Yang et al. 2019).

Diversification in this sense is an adaptive strategy rooted in prehistory. The broadening of the resource base is best known in the Late Pleistocene shift from large game hunting to more diverse diets, an adaptive shift known as the Broad Spectrum Revolution (Flannery 1969, Zeder 2012). A significant benefit of diversification, compared to specialization and intensification, lies in the reduction of vulnerability in the face of unpredictable changes, achieved by the segmentation of the risk of failure. Exploiting a wider range of plant and animal species or broader and more varied areas reduces the risk of shortages that endanger socio-cultural continuity (Halstead and O'Shea 1989). In smallscale societies, the diversification of resource bases can involve: (1) using a mixture of domesticated plants and livestock (including various strains of the same cultivated species); (2) diversifying the use of space (e.g., dispersed fields or farming in a variety of places); and/or (3) relying on non-domesticated secondary, fallback resources (or "famine foods," including wild resources in the immediate environment; O'Shea 1989).

A rich literature on post-collapse societies also illustrates how diversity in subsistence has enabled adaptation and socio-cultural revitalization following the demise of centralized authorities and organization (Cooper 2006, Nichols and Weber 2006, Schwartz and Nichols 2010). Conversely, it has been observed that the lack of diversification, e.g., in the forms of monocultures of crops or economic systems, can prove to be fragile and maladaptive in the long-term (Scott 1998).

Significant diversity is also observed in the material culture of small-scale societies, varying for the most part within socially inherited in-group boundaries, but always in practical response to the local environment and organizational constraints (Chatters 1987). This is, for example, visible in the exceptionally long, and for large part complete, record of stone tool production, which indicates technological change through time in response to variable sets of interconnected regional and supra-regional factors, such as local raw material availability, subsistence strategies, population growth, and environmental change (e.g., Bousman 1993, Manninen and Knutsson 2014). Although the stone tool record indicates that diverse environmental and sociocultural drivers have resulted in strikingly similar technological solutions between culturally disconnected groups (O'Brien et al. 2018), it also shows a markedly heterogeneous record of stone tool types over vast temporal and geographical scales.

\section{Evolving precautionary heuristics}

Next to diversification, another principle for adaptation we identified is the use of precautionary heuristics. When societies adapt to a new or changed ecological niche, they generally develop various rules of thumb, norms, and heuristics to guide their interaction with it. Among the heuristics, some small-scale societies rely on simple cues, including seasonal knowledge and ecological events, such as the flowering of particular plants or the arrival of migratory birds, to open and close seemingly unrelated resource exploitation seasons (Lansing 1987, Colding and Folke 2001, Prober et al. 2011, Smyth and Isherwood 2016). This mode of decision making that makes heuristic use of even simple environmental cues is also called ecological rationality (Gigerenzer and Todd 1999, Marewski et al. 2010, Todd and Gigerenzer 2012). By relying on statistical regularities in everyday environments, many societies have evolved to use relatively simple environmental signals as guides for foraging and natural resource management or exploitation, among other activities.

One highly salient form of heuristics, we argue, is the application of precautionary measures or norms, that is, the use of and learning from what can be called "applied precautionary principles." These are heuristics that prohibit or otherwise seek to constrain behaviors, such as violations of norms or perilous actions. As with diversification, precautionary heuristics have evolved to be widely applicable and precautionary rules or heuristics found at scales ranging from individual behavior to group or society-level norms.

For instance, foraging cultures have developed and used heuristics, including precautionary strategies and taboos, to deal with uncertain environments (Colding and Folke 2001, Henrich and Henrich 2010, Kaaronen 2020). In traditional Finnish 
foraging cultures, for example, foragers have been documented to rely on precautionary heuristics that prohibit the picking of unknown mushrooms or mushrooms with certain traits (such as color) to set clear and well-defined boundaries for safe foraging (Kaaronen 2020). At the group level and by way of other examples, precautionary traditions and taboos have been documented as being used in protection against the consumption of dangerous marine toxins (Henrich and Henrich 2010), the governance of sustained marine resource management (Johannes 1978, Hens 2006, Hickey 2007, Smyth and Isherwood 2016), the management of livestock and pastoral risks (Roe 2020), the placing of temporary restrictions on farming to prevent the overworking of land (Sarfo-Mensah and Oduro 2007), and the setting of boundaries for protected forest patches such as sacred groves (Bhagwat and Rutte 2006, Sarfo-Mensah and Oduro 2007, Dudley et al. 2009, Nganso et al. 2012, Yuan et al. 2020).

Elsewhere, such practices have helped to manage risk at individual and collective levels by, e.g., using precautionary rules to prevent the accumulation of debt (Graeber 2012) or by experimenting with natural systems in ways that prevent irreversible mistakes (Read and Taleb 2014). Another case of precautionary heuristics is the well-documented don't put all your eggs in the same basket practice to mitigate risk of ruin by diversifying assets or subsistence strategies (Halstead and O'Shea 1989, 2004).

Although the question of how far precautionary cultural practices specifically have promoted nature conservation is hotly debated (Colding and Folke 1997, 2001, Smith and Wishnie 2000, Sarfo-Mensah and Oduro 2007), less dubious is the evidence that precaution and precautionary heuristics have a long history in guiding resource management, consumption, and creating the socio-cultural preconditions for robust systems of selfgovernance (Lansing 2006). Precautionary heuristics and uncertainty management have, however, received insufficient focus in studies on socio-cultural evolution, sustainability science, and adaptive management, and we pinpoint this as a target for future inquiry.

\section{APPLYING THE KEY STRATEGIES TO CLIMATE AND ECOSYSTEM DISRUPTION}

We have identified multi-scale diversification and socially learned precautionary heuristics as two key principles that have guided human adaptation to variable environments in the past. We now discuss contemporary developments that are directly at odds with these principles. We are afraid that human adaptation to the changing ecosystems and climates of the Anthropocene may be severely hampered if diversification and precaution are not taken more seriously.

Prevailing global trends have step-by-step minimized processes that value diversification and precaution. This is well-illustrated by the global production ecosystem (GPE) concept (Nyström et al. 2019), which states that contemporary global economic development is characterized by:

1. Homogenization and simplification of resource bases (and erasure of local traditions and practices), resulting in biotic homogenization, habitat simplification, and standardized food supply.

2. Increased global connectivity and related homogenization of socio-cultural practices and the dissolution of socio- technical borders, resulting in socio-cultural and economic homogeneity.

3. Centralization, financialization, and intensification of modes of resource production and extraction, resulting in the kind of hubristic technological and economic development and short-term optimization that pays little heed to precaution in the long term.

Consistent with the related concepts of planetary boundaries and the Anthropocene, the GPE aims to describe the current predicament and its global-level solutions with broad strokes. However, we acknowledge that the GPE does not apply uniformly to all modern societies. For example, Japanese culture retains many features rooted in locality and tradition (Rosser et al. 1999, Tanimoto 2006), whereas otherwise very much part of the global economic system. Likewise, many local societies (although decreasingly so) maintain longstanding practices that do not conform to the principles of the GPE (Watson 2019). Meanwhile, it is equally true that some small-scale societies have used strategies that have historically led to reckless and unsustainable resource use (Smith and Wishnie 2000). Unsustainability is not a trait exclusive to GPE societies. Therefore, as we have emphasized, modern societies must not be naive in emulating unmodified solutions from small-scale societies. Although we use GPE as illustrative of the current global predicament and as an antithesis to small-scale societies and local communities, a continuum exists between the two extremes into which most societies fall.

\section{From small-scale societies to high reliability management}

The GPE is practically antithetical to the past adaptive principles of multi-level diversification and precaution. Arguably, alternative modalities for environmental management, i.e., ones that take diversification and precaution more seriously, are required to meet the challenges of the Anthropocene. Fortunately, the GPE mindset is far from the only modern template for managing risk and uncertainty. In fact, prevailing risk management strategies in critical infrastructures offer an alternative that more faithfully emulates those principles that have proved adaptive in the past. Therefore, to tie the discussion of past adaptive principles to the present, we describe the roles diversification and precaution play in the high reliability management of critical infrastructures.

Critical infrastructures, like large-scale water and electricity systems, have often been rightfully criticized for their adverse environmental impacts. Less understood or appreciated are the positive real-time impacts of the control-room operations of these systems and the vital functions these control rooms play in the dual task of maintaining service reliability, while at the same time maintaining ecosystem functions and processes upon which they depend (Weinstein et al. 2007). We emphasize that real-time control room behavior in the most critical hubs of contemporary societies (e.g., power plants, water and waste management systems, energy distribution companies) demonstrates the same kind of adaptive capacities seen in smaller scale societies.

Research in high reliability management illustrates how real-time operators of critical infrastructures not only embrace macroprinciples for systemwide reliability and safety, but also focus on evolving better practices for better real-time management not covered by existing macro-principles (Roe and Schulman 2008, 
Fig. 1. Today's high reliability management of infrastructures, in terms of input (A), process (B), and output (C) variance.

\section{High Reliability Management}

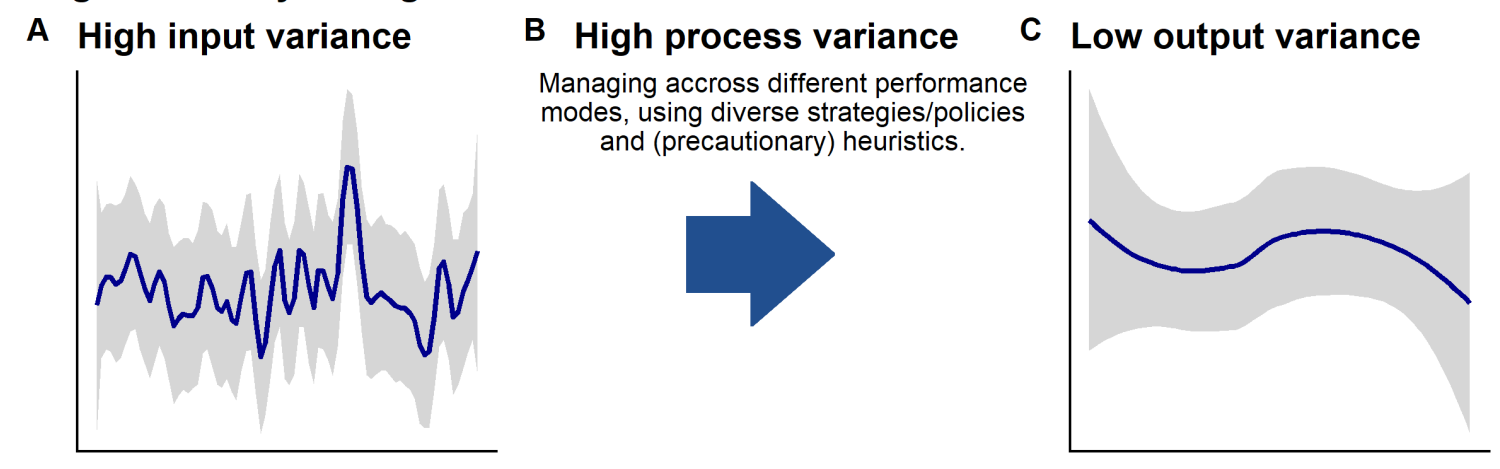

2016, 2018). Notably, these principles and practices include: (1) diverse strategies that allow high variance in input and process, while output variance still remains low and stable, and (2) precautionary hazard-driven adaptation, which necessitates a constant vigilance and preparedness for multiple threats and the ever-present possibility of error and adaptive learning (Roe and Schulman 2008, 2016).

The first strategy, managing high input variance with high process variance for low and stable output variance, emulates the adaptive principle of multi-level diversification. Critical infrastructure operations are ever more exposed to volatile inputs such as markets and climate change (high input variance), to which they have to adapt with increasingly diversified management options and processes (high process variance) to secure an oftenmandated stable service provision (low output variance), especially when the composition (as distinct from the variance) of those outputs changes over time (Fig. 1). These diverse strategies can rely considerably on variable forms of local, practical, and tacit knowledge, typically described as experts developing situation awareness (or "having the bubble;" Roberts and Rousseau 1989). Note that these variable responses to high variability environments are considerably different than the GPE mindset of managing environmental variability through homogenization and intensification.

A second key strategy of high reliability management involves hazard preparedness and error avoidance, emulating the precautionary heuristics that evolved in small-scale societies. Infrastructure operators with skin in the game (Taleb and Sandis 2014) must know quickly and with trained intuition not just what causes system failure but also possible precursors to these causes. Some heuristics preclude certain events from ever happening, identifying disturbances that "must never happen ever" for the system in question (Roe 2020). This makes them especially error avoiding, placing a high premium on preparedness, precaution, adaptation, and real-time resilience. Team situation awareness in moving across different performance modes as conditions change becomes an important collective set of practices and skills for real-time response (Roe and Schulman 2018).
We highlight these similarities (Table 1) between past adaptive capacities and high reliability management to point to some important lessons on how contemporary societies should seek to manage and not just cope with complex, uncertain environments and landscapes. In sharp contrast to the GPE, which seeks full control of input variance and process variance to secure a steady growing output of food and commodities and disregards precautionary heuristics in its attempt to optimize resource extraction in the short-term, the smaller-scale societies and critical infrastructures we have described feature diverse and precautionary evolving practices built into conventions and employed by knowledgeable actors. Unfortunately, their unique knowledge of the respective systems has often been dismissed as traditional or Indigenous in the case of smaller-scale societies, or as procedural and automatic in larger socio-technical systems.

Table 1. Past and present applications of the principles of adaptive capacity.

\begin{tabular}{|c|c|c|}
\hline $\begin{array}{l}\text { Principle of } \\
\text { adaptive } \\
\text { capacity }\end{array}$ & Past application & Modern application \\
\hline $\begin{array}{l}\text { Multi-level } \\
\text { diversification }\end{array}$ & $\begin{array}{l}\text { Don't put all your eggs in } \\
\text { the same basket }\end{array}$ & $\begin{array}{l}\text { High input variance } \\
\text { managed with high process } \\
\text { variance for low and stable } \\
\text { output variance, for } \\
\text { example, when output } \\
\text { composition is changing } \\
\text { over time }\end{array}$ \\
\hline $\begin{array}{l}\text { Precautionary } \\
\text { heuristics }\end{array}$ & $\begin{array}{l}\text { Ecologically rational } \\
\text { behavior: using simple } \\
\text { environmental cues/rules to } \\
\text { make efficient and precise } \\
\text { decisions }\end{array}$ & $\begin{array}{l}\text { Knowledge of precluded } \\
\text { precursors and operational } \\
\text { errors }\end{array}$ \\
\hline
\end{tabular}

\section{Caveats and the response of requisite variety}

Due to abrupt and rapid climate and ecosystem disruptions, the professional or traditional rules of thumb we have been alerting the reader to might suddenly become outdated. Some features of these unique knowledge bases may lose their adaptive capacity as 
local biodiversity (and thus ecological cues) degrade, invasive species take over, or when climate change renders previously adaptive ecological cues unrecognizable.

Accordingly, when learning from these knowledge platforms, we must focus on the more robust and generalizable principles and patterns to guide decision-making strategies. This focus on robustness is, in turn, a particularly compelling rationale for maintaining a requisite variety of strategies for adaptation: when one strategy fails, we must have a pool of others to choose from. It is requisite variety in the options and strategies (the process variance) with which to respond to unpredictable input variance (a key feature of the Anthropocene) that we must focus on if the aim is to ensure a low and stable variance around environmental outputs, defined here as ecosystem services and benefits as well as the underlying ecosystem processes and functions.

Identifying and maintaining a rich pool of adaptive strategies allows us to test, refine, adopt, and upscale these strategies through adaptive management and local experimental governance (Lee 1994). Through diverse local strategies that resonate with the principles described, we are better able to adapt to uncertainties and risks posed by climate and biodiversity crises. Acknowledging that there is no optimal way to prepare for an uncertain future (because defining an optimal strategy would require knowing the state space of possible futures; Kay and King 2020), maintaining and sustaining diversity, precaution, and redundancy become ever the more vital.

By increasing variety in the means of operation, production, and practices, we are able to systematically increase the resilience, i.e., the capacity of a system to deal with dynamic change and continue to develop (Folke et al. 2010), of modern socio-cultural systems. To deal with an uncertain future, we are required, as we have seen, to maintain requisite variety in these systems. Currently and as described, the GPE works primarily to reduce requisite variety through processes of homogenization, connectedness, and centralization, and is disregarding precautionary heuristics in its attempt to optimize resource production in the short-term (Fig. 2).

We fully acknowledge that even local societies and regional sociotechnical systems with robust adaptation strategies will likely struggle with adapting to the uncertain climates and ecosystems of the near future. Indeed, the fragility of contemporary socioeconomic systems has become evident during the COVID-19 crisis in the time of this writing (2020-2021), which has exposed the fault lines of global value chains and technological interdependencies (Fortunato 2020). We maintain, however, that even here the processes of diversification and precaution as advocated in this perspective better prevent large-scale cascades of systemic failures with irreversible consequences. Indeed, wherever environments have been uncertain, adaptive strategies have also been variable. As such, small or local failures in adaptation can even be more usefully informative when the causal mechanisms underlying them are better understood (Popper 1957).

\section{CONCLUSION}

Trends in today's world are well described by the Global Production Ecosystem (GPE) concept, characterized by homogenization, interconnectivity, intensification and centralization.
These trends are evident on a global scale. The logic of this GPE mindset is to operate environments and resource extraction so as to ensure stabilized outputs and services. Its input and process variance (think: guns, guards and gates) are controlled or otherwise regulated to maintain a steady and stable output variance. The long-term historical evidence suggests that this planetary gamble is now on an epochal scale. Today's increasingly monolithic strategies seek to minimize diversification and precautionary measures, two persisting adaptive capacities that we have identified in past human societies and in contemporary high reliability management systems.

Fig. 2. Today's predicament: the choice between a high risk (homogenous, intensified, and centralized) and a low risk (diverse, variable, precautionary) future.

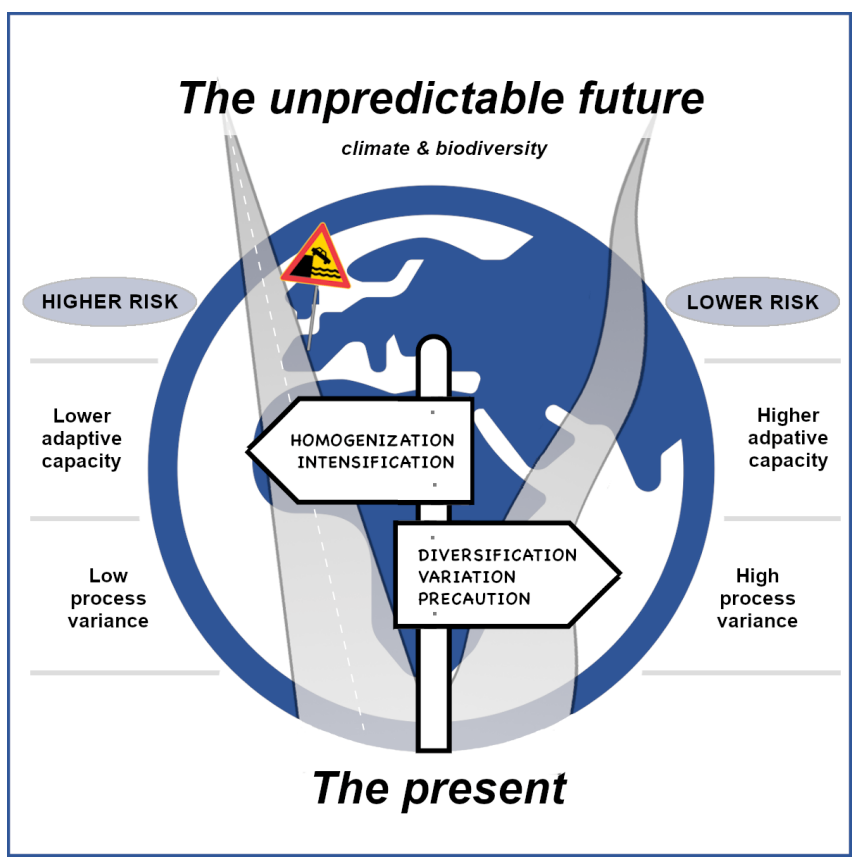

The stakes in the GPE gamble are high because historical records suggest that past processes of homogenization, interconnectivity, and centralization, across a spectrum of empirical cases, are associated with socio-ecological fragility or collapse (Scott 1998, Schwartz and Nichols 2010, Faulseit 2016), and are antithetical to some key adaptive capacities identified in past societies. Moreover, homogenization, interconnectivity, and centralization may induce countervailing forces, not least of which is high ecological and climatic uncertainty. The upshot - and the irony is not lost here - is that the uncertainty produced by the GPE itself increases the demand for a variety of localized and adaptive strategies to cope with the increase in input variability (such as climate and ecosystem change). More bluntly, no one should put all their eggs in the GPE basket on the bet that homogenization, connectivity, and centralization will win the day across the globe anyway.

Responses to this article can be read online at: https://www.ecologyandsociety.org/issues/responses. php/12476 


\section{Acknowledgments:}

Funding from the Academy of Finland's Strategic Research Council grant no. 312623 is gratefully acknowledged. ROK acknowledges funding from the University of Helsinki Doctoral Programme in Social Sciences.

\section{Data Availability:}

Datalcode sharing is not applicable to this article because no new datalcode were created or analyzed in this study.

\section{LITERATURE CITED}

Antal, M., and J. I. Hukkinen. 2010. The art of the cognitive war to save the planet. Ecological Economics 69(5):937-943. https:// doi.org/10.1016/j.ecolecon.2010.01.002

Ashby, W. R. 1960. Design for a brain: the origin of adaptive behaviour. Springer, New York, New York, USA. https://doi. org/10.5962/bhl.title.7309

Barnosky, A. D., E. A. Hadly, J. Bascompte, E. L. Berlow, J. H. Brown, M. Fortelius, W. M. Getz, J. Harte, A. Hastings, P. A. Marquet, N. D. Martinez, A. Mooers, P. Roopnarine, G. Vermeij, J. W. Williams, R. Gillespie, J. Kitzes, C. Marshall, N. Matzke, D. P. Mindell, E. Revilla, and A. B. Smith. 2012. Approaching a state shift in Earth's biosphere. Nature 486(7401):52-58. https://doi. org/10.1038/nature11018

Barnosky, A. D., E. A. Hadly, P. Gonzalez, J. Head, P. D. Polly, A. M. Lawing, J. T. Eronen, D. D. Ackerly, K. Alex, E. Biber, J. Blois, J. Brashares, G. Ceballos, E. Davis, G. P. Dietl, R. Dirzo, H. Doremus, M. Fortelius, H. W. Greene, J. Hellmann, T. Hickler, S. T. Jackson, M. Kemp, P. L. Koch, C. Kremen, E. L. Lindsey, C. Looy, C. R. Marshall, C. Mendenhall, A. Mulch, A. M. Mychajliw, C. Nowak, U. Ramakrishnan, J. Schnitzler, K. D. Shrestha, K. Solari, L. Stegner, M. A. Stegner, N. C. Stenseth, M. H. Wake, and Z. Zhang. 2017. Merging paleobiology with conservation biology to guide the future of terrestrial ecosystems. Science 355(6325). https://doi.org/10.1126/science.aah4787

Barnosky, A. D., N. Matzke, S. Tomiya, G. O. U. Wogan, B. Swartz, T. B. Quental, C. Marshall, J. L. McGuire, E. L. Lindsey, K. C. Maguire, B. Mersey, and E. A. Ferrer. 2011. Has the Earth's sixth mass extinction already arrived? Nature 471(7336):51-57. https://doi.org/10.1038/nature09678

Barnosky, A., and E. Hadly. 2015. End game: tipping point for planet Earth? Harpercollins, New York, New York, USA.

Barsbai, T., D. Lukas, and A. Pondorfer. 2021. Local convergence of behavior across species. Science 371(6526):292-295. https://doi. org/10.1126/science.abb7481

Bateson, G. 2000. Steps to an ecology of mind: collected essays in anthropology, psychiatry, evolution, and epistemology. University of Chicago Press, Chicago, Illinois, USA. https://doi. org/10.7208/chicago/9780226924601.001.0001

Bhagwat, S. A., and C. Rutte. 2006. Sacred groves: potential for biodiversity management. Frontiers in Ecology and the Environment 4(10):519-524. https://doi.org/10.1890/1540-9295 (2006)4[519:SGPFBM]2.0.CO;2
Bousman, C. B. 1993. Hunter-gatherer adaptations, economic risk and tool design. Lithic Technology 18(1-2):59-86. https://doi. org/10.1080/01977261.1993.11720897

Boyd, R., P. J. Richerson, and J. Henrich. 2011. The cultural niche: why social learning is essential for human adaptation. Proceedings of the National Academy of Sciences 108(Supplement 2):10918-10925. https://doi.org/10.1073/pnas.1100290108

Brewer, J., and F. Riede. 2018. Cultural heritage and climate adaptation: a cultural evolutionary perspective for the Anthropocene. World Archaeology 50(4):554-569. https://doi. org/10.1080/00438243.2018.1527246

Bringezu, S., A. Ramaswami, H. Schandl, M. O'Brien, R. Pelton, J. Acquatella, E. Ayuk, A. Chiu, R. Flanegin, J. Fry, S. Giljum, S. Hashimoto, S. Hellweg, K. Hosking, Y. Hu, M. Lenzen, M. Lieber, S. Lutter, A. Miatto, A. Singh Nagpure, M. Obersteiner, E. van Oers, L., Pfister, S., Pichler, P., Russell, A., Spini, L., Tanikawa, H., van der Voet, H. Weisz, J. West, A. Wiijkman, B. Zhu, and R. Zivy. 2017. Assessing global resource use: a system approach to resource efficiency and pollution reduction. International Resource Panel, United Nations Environment Programme, Nairobi, Kenya. [online] URL: https://wedocs.unep. org/bitstream/handle/20.500.11822/27432/resource use.pdf? sequence $=1 \&$ is Allowed $=\mathrm{y}$

Caselli, F., M. Koren, M. Lisicky, and S. Tenreyro. 2020. Diversification through trade. Quarterly Journal of Economics 135(1):449-502. https://doi.org/10.1093/qje/qjz028

Chakrabarty, D. 2009. The climate of history: four theses. Critical Inquiry 35(2):197-222. https://doi.org/10.1086/596640

Chatters, J. C. 1987. Hunter-gatherer adaptations and assemblage structure. Journal of Anthropological Archaeology 6(4):336-375. https://doi.org/10.1016/0278-4165(87)90005-5

Colding, J., and C. Folke. 1997. The relations among threatened species, their protection, and taboos. Conservation Ecology 1(1):6. https://doi.org/10.5751/ES-00018-010106

Colding, J., and C. Folke. 2001. Social taboos: "invisible" systems of local resource management and biological conservation. Ecological Applications 11(2):584-600. https://doi.org/10.1890/1051-0761 (2001)011[0584:stisol]2.0.co;2

Conant, R. C., and W. R. Ashby. 1970. Every good regulator of a system must be a model of that system. International Journal of Systems Science 1(2):89-97. https://doi.org/10.1080/00207727008920220

Cooper, L. 2006. The demise and regeneration of Bronze Age urban centers in the Euphrates Valley of Syria. Pages 18-37 in G. M. Schwartz and J. J. Nichols, editors. After collapse: the regeneration of complex societies. University of Arizona Press, Tucson, Arizona, USA.

Costanza, R., L. J. Graumlich, and W. Steffen. 2007. Sustainability or collapse?: an integrated history and future of people on Earth. Mit Press, Cambridge, Massachusetts, USA. https://doi.org/10.7551/mitpress/6572.001.0001

Díaz, S., J. Settele, E. S. Brondízio, H. T. Ngo, J. Agard, A. Arneth, P. Balvanera, K. A. Brauman, S. H. M. Butchart, K. M. A. Chan, L. A. Garibaldi, K. Ichii, J. Liu, S. M. Subramanian, G. F. Midgley, P. Miloslavich, Z. Molnár, D. Obura, A. Pfaff, S. Polasky, 
A. Purvis, J. Razzaque, B. Reyers, R. R. Chowdhury, Y.-J. Shin, I. Visseren-Hamakers, K. J. Willis, and C. N. Zayas. 2019. Pervasive human-driven decline of life on Earth points to the need for transformative change. Science 366(6471). https://doi. org/10.1126/science.aax3100

Dirzo, R., H. S. Young, M. Galetti, G. Ceballos, N. J. B. Isaac, and B. Collen. 2014. Defaunation in the Anthropocene. Science 345(6195):401-406. https://doi.org/10.1126/science.1251817

Dudley, N., L. Higgins-Zogib, and S. Mansourian. 2009. The links between protected areas, faiths, and sacred natural sites. Conservation Biology 23(3):568-577. https://doi.org/10.1111/ j.1523-1739.2009.01201.x

Ellis, E. C. 2016. Ecology in an anthropogenic biosphere. Ecological Monographs 85:287-331. https://doi.org/10.1890/14-2274.1

Ellis, F. 2000. The determinants of rural livelihood diversification in developing countries. Journal of Agricultural Economics 51 (2):289-302. https://doi.org/10.1111/j.1477-9552.2000.tb01229.x

Emmett, R., and T. Lekan. 2016. Whose Anthropocene? Revisiting Dipesh Chakrabarty's "four theses". Rachel Carson Center for Environment and Society, Munich, Germany. [online] URL: http://www.environmentandsociety.org/sites/default/ files/2015 new final.pdf

Faulseit, R. K. 2016. Beyond collapse: archaeological perspectives on resilience, revitalization, and transformation in complex societies. Southern Illinois University Press, Carbondale, Illinois, USA.

Flannery, K. V. 2008. Origins and ecological effects of early domestication in Iran and the Near East. Pages 73-100 in P. J. Ucko and G. W. Dimbleby, editors. The domestication and exploitation of plants and animals. Routledge, New York, New York, USA. https://doi.org/10.4324/9781315131825-7

Foley, J. A., N. Ramankutty, K. A. Brauman, E. S. Cassidy, J. S. Gerber, M. Johnston, N. D. Mueller, C. O’Connell, D. K. Ray, P. C. West, C. Balzer, E. M. Bennett, S. R. Carpenter, J. Hill, C. Monfreda, S. Polasky, J. Rockström, J. Sheehan, S. Siebert, D. Tilman, and D. P. M. Zaks. 2011. Solutions for a cultivated planet. Nature 47(7369):337-342. https://doi.org/10.1038/nature10452

Foley, R. A., and M. Mirazón Lahr. 2011. The evolution of the diversity of cultures. Philosophical Transactions of the Royal Society B: Biological Sciences 366(1567):1080-1089. https://doi. org/10.1098/rstb.2010.0370

Folke, C., S. R. Carpenter, B. Walker, M. Scheffer, T. Chapin, and J. Rockström. 2010. Resilience thinking: integrating resilience, adaptability and transformability. Ecology and Society 15(4):20. https://doi.org/10.5751/ES-03610-150420

Fortunato, P. 2020. How COVID-19 is changing global value chains. United Nations Conference on Trade and Development (UNCTAD), Geneva, Switzerland. [online] URL: https://unctad. org/news/how-covid-19-changing-global-value-chains

Gigerenzer, G., and P. M. Todd. 1999. Fast and frugal heuristics: the adaptive toolbox. Pages 3-34 in G. Gigerenzer, P. M. Todd, and The ABC Research Group, editors. Simple heuristics that make us smart. Oxford University Press, Oxford, UK.
Graeber, D. 2012. Debt: the first 5000 years. Penguin, London, UK.

Halstead, P., and J. O'Shea. 1989. Introduction: cultural responses to risk and uncertainty. Pages 1-7 in P. Halstead and J. O'Shea, editors. Bad year economics: cultural responses to risk and uncertainty. Cambridge University Press, Cambridge, UK. https://doi.org/10.1017/cbo9780511521218.002

Halstead, P., and J. O’Shea. 1989. Bad year economics: cultural responses to risk and uncertainty. Cambridge University Press, Cambridge, UK. https://doi.org/10.1017/CBO9780511521218

Hansen, J., M. Sato, P. Kharecha, K. von Schuckmann, D. J. Beerling, J. Cao, S. Marcott, V. Masson-Delmotte, M. J. Prather, E. J. Rohling, J. Shakun, P. Smith, A. Lacis, G. Russell, and R. Ruedy. 2017. Young people's burden: requirement of negative CO2 emissions. Earth System Dynamics 8(3):577-616. https://doi. org/10.5194/esd-8-577-2017

Henrich, J. 2016. The secret of our success: how culture is driving human evolution, domesticating our species, and making us smarter. Princeton University Press, Princeton, New Jersey, USA. https://doi.org/10.2307/j.ctvc77f0d.3

Henrich, J., and N. Henrich. 2010. The evolution of cultural adaptations: Fijian food taboos protect against dangerous marine toxins. Proceedings of the Royal Society B: Biological Sciences 277(1701):3715-3724. https://doi.org/10.1098/rspb.2010.1191

Hens, L. 2006. Indigenous knowledge and biodiversity conservation and management in Ghana. Journal of Human Ecology 20(1):21-30. https://doi.org/10.1080/09709274.2006.11905897

Hickey, F. R. 2007. Traditional marine resource management in Vanuatu: worldviews in transformation. Pages 147-168 in N. Hagan, B. Neis, and I. G. Baird, editors. Fishers' knowledge in fisheries science and management, UNESCO, Paris, France.

Hill, K., and R. Boyd. 2021. Behavioral convergence in humans and animals. Science 371(6526):235-236. https://doi.org/10.1126/ science.abf7572

Hoppitt, W., and K. N. Laland. 2013. Social learning: an introduction to mechanisms, methods, and models. Princeton University Press, Princeton, New Jersey, USA.

Järvensivu, P., T. Toivanen, T. Vadén, V. Lähde, A. Majava, and J. T. Eronen. 2018. Global sustainable development report 2019 drafted by the Group of independent scientists. Invited background document on economic transformation, to chapter: transformation: the economy. BIOS Research Unit, Helsinki, Finland. [online] URL: https://bios.fi/bios-governance of economic transition.pdf

Johannes, R. E. 1978. Traditional marine conservation methods in Oceania and their demise. Annual Review of Ecology and Systematics 9(1):349-364. https://doi.org/10.1146/annurev. es.09.110178.002025

Kaaronen, R. O. 2020. Mycological rationality: heuristics, perception and decision-making in mushroom foraging. Judgment and Decision Making 15(5):630-647. https://doi. org/10.31234/osf.io/7g8er 
Kay, J. A., and M. A. King. 2020. Radical uncertainty: decisionmaking beyond the numbers. Bridge Street, London, UK.

Keck, M., and P. Sakdapolrak. 2013. What is social resilience? Lessons learned and ways forward. Erdkunde 67(1):5-19. https:// doi.org/10.3112/erdkunde.2013.01.02

Kelly, R. L. 2013. The lifeways of hunter-gatherers: the foraging spectrum. Cambridge University Press, Cambridge, UK.

Krausmann, F., D. Wiedenhofer, C. Lauk, W. Haas, H. Tanikawa, T. Fishman, A. Miatto, H. Schandl, and H. Haberl. 2017. Global socioeconomic material stocks rise 23 -fold over the 20th century and require half of annual resource use. Proceedings of the National Academy of Sciences 114(8):1880-1885. https://doi. org/10.1073/pnas.1613773114

Laland, K. N. 2018. Darwin's unfinished symphony: how culture made the human mind. Princeton University Press, Princeton, New Jersey, USA. https://doi.org/10.2307/j.ctv39x6r5

Lansing, J. S. 1987. Balinese "water temples" and the management of irrigation. American Anthropologist 89(2):326-341. https:// doi.org/10.1525/aa.1987.89.2.02a00030

Lansing, J. S. 2006. Perfect order: recognizing complexity in Bali. Princeton University Press, Princeton, New Jersey, USA.

Lee, K. N. 1994. Compass and gyroscope: integrating science and politics for the environment. Island, Washington, D.C., USA.

Manninen, M. A., and K. Knutsson. 2014. Lithic raw material diversification as an adaptive strategy - technology, mobility, and site structure in Late Mesolithic northernmost Europe. Journal of Anthropological Archaeology 33:84-98. https://doi.org/10.1016/ j.jaa.2013.12.001

Marcott, S. A., J. D. Shakun, P. U. Clark, and A. C. Mix. 2013. A reconstruction of regional and global temperature for the past 11,300 years. Science 339(6124):1198-1201. https://doi.org/10.1126/ science. 1228026

Marewski, J. N., W. Gaissmaier, and G. Gigerenzer. 2010. Good judgments do not require complex cognition. Cognitive Processing 11(2):103-121. https://doi.org/10.1007/s10339-009-0337-0

Mathew, S., and C. Perreault. 2015. Behavioural variation in 172 small-scale societies indicates that social learning is the main mode of human adaptation. Proceedings of the Royal Society B: Biological Sciences 282(1810):20150061. https://doi.org/10.1098/ rspb.2015.0061

McAnany, P. A., and N. Yoffee. 2009. Questioning collapse: human resilience, ecological vulnerability, and the aftermath of empire. Cambridge University Press, Cambridge, UK.

Mesoudi, A. 2011. Cultural evolution: how Darwinian theory can explain human culture and synthesize the social sciences. University of Chicago Press, Chicago, Illinois, USA.

Nganso, T. B., R. Kyerematen, and D. Obeng-Ofori. 2012. Review of biodiversity in sacred groves in Ghana and implications on conservation. Pages 1-10 in Current trends in ecology, CABI, Wallingford, UK.

Nichols, J. J., and J. A. Weber. 2006. Amorites, onagers, and social reorganization in Middle Bronze Age Syria. Pages 38-57 in G. M.
Schwartz and J. J. Nichols, editors. After collapse: the regeneration of complex societies. University of Arizona Press, Tucson, Arizona, USA.

Nyström, M., J.-B. Jouffray, A. V. Norström, B. Crona, P. Søgaard Jørgensen, S. R. Carpenter, Ö. Bodin, V. Galaz, and C. Folke. 2019. Anatomy and resilience of the global production ecosystem. Nature 575(7781):98-108. https://doi.org/10.1038/s41586-019-1712-3

O’Brien, M. J., B. Buchanan, and M. I. Eren. 2018. Convergent evolution in stone-tool technology. Vienna Series in Theoretical Biology. MIT Press, Cambridge, Massachusetts, USA.

Ordonez, A., and J.-C. Svenning. 2016. Strong paleoclimatic legacies in current plant functional diversity patterns across Europe. Ecology and Evolution 6(10):3405-3416. https://doi. org/10.1002/ece3.2131

Organisation for Economic Co-operation and Development (OECD), and World Trade Organization (WTO). 2019. Aid for trade at a glance 2019: economic diversification and empowerment. OECD, Paris, France. https://doi.org/10.1787/7c2d5aa8$\underline{\mathrm{pt}}$

O'Shea, J. 1989. The role of wild resources in small-scale agricultural systems: tales from the lakes and the plains. Pages 57-67 in P. Halstead and J. O'Shea, editors. Bad year economics: cultural responses to risk and uncertainty. https://doi. org/10.1017/cbo9780511521218.005

Perreault, C. 2012. The pace of cultural evolution. PLoS One 7 (9):e45150. https://doi.org/10.1371/journal.pone.0045150

Popper, K. 1957. The poverty of historicism. Routledge, New York, New York, USA.

Prentiss, W. C., and J. C. Chatters. 2003. Cultural diversification and decimation in the prehistoric record. Current Anthropology 44(1):33-58. https://doi.org/10.1086/344488

Prober, S. M., H. O'Connor, and F. J. Walsh. 2011. Australian Aboriginal peoples' seasonal knowledge: a potential basis for shared understanding in environmental management. Ecology and Society 16(2):12. https://doi.org/10.5751/es-04023-160212

Read, R., and N. N. Taleb. 2014. Religion, heuristics and intergenerational risk-management. Economics in Practice 11 (2):219-226.

Rist, L., A. Felton, M. Nyström, M. Troell, R. A. Sponseller, J. Bengtsson, H. Österblom, R. Lindborg, P. Tidåker, D. G. Angeler, R. Milestad, and J. Moen. 2014. Applying resilience thinking to production ecosystems. Ecosphere 5(6):art73. https://doi. org/10.1890/ES13-00330.1

Roberts, K. H., and D. M. Rousseau. 1989. Research in nearly failure-free, high-reliability organizations: having the bubble. IEEE Transactions on Engineering Management 36(2):132-139. https://doi.org/10.1109/17.18830

Roe, E. 2020. A new policy narrative for pastoralism? Pastoralists as reliability professionals and pastoralist systems as infrastructure. STEPS working paper 113. ESRC STEPS Centre, Brighton, UK. [online] URL: https://www.ids.ac.uk/publications/ a-new-policy-narrative-for-pastoralism-pastoralists-as-reliabilityprofessionals-and-pastoralist-systems-as-infrastructure/ 
Roe, E., and P. R. Schulman. 2008. High reliability management: operating on the edge. Stanford University Press, Stanford, California, USA.

Roe, E., and P. Schulman. 2016. Reliability and risk: the challenge of managing interconnected infrastructures. Stanford University Press, Stanford, California, USA. https://doi.org/10.11126/ stanford/9780804793933.001.0001

Roe, E., and P. R. Schulman. 2018. A reliability and risk framework for the assessment and management of system risks in critical infrastructures with central control rooms. Safety Science 110:80-88. https://doi.org/10.1016/j.ssci.2017.09.003

Rosser, M. V., J. Barkley Rosser, Jr., and K. L. Kramer, Jr. 1999. The new traditional economy: a new perspective for comparative economics? International Journal of Social Economics 26 (6):763-778. https://doi.org/10.1108/03068299910227318

Sarfo-Mensah, P., and W. Oduro. 2007. Traditional natural resources management practices and biodiversity conservation in Ghana: a review of local concepts and issues on change and sustainability. FEEM Working Paper no. 90.2007. https://doi. org/10.2139/ssrn.1017238

Schellnhuber, H. J., S. Rahmstorf, and R. Winkelmann. 2016. Why the right climate target was agreed in Paris. Nature Climate Change 6(7):649-653. https://doi.org/10.1038/nclimate3013

Schwartz, G. M., and J. J. Nichols. 2010. After collapse: the regeneration of complex societies. University of Arizona Press, Tucson, Arizona, USA.

Scott, J. C. 1998. Seeing like a state: how certain schemes to improve the human condition have failed. Yale University Press, New Haven, Connecticut, USA. https://doi.org/10.2307/j. $\underline{\text { ctvxkn } 7 \mathrm{ds}}$

Smith, E. A., and M. Wishnie. 2000. Conservation and subsistence in small-scale societies. Annual Review of Anthropology 29 (1):493-524. https://doi.org/10.1146/annurev.anthro.29.1.493

Smyth, D., and M. Isherwood. 2016. Protecting sea country: Indigenous people and marine protected areas in Australia. Pages 307-325 in G. Wescott and J. Fitzsimons, editors. Big, bold and blue: lessons from Australia's Marine Protected Areas. https://doi. org/10.1071/9781486301959

Steffen, W., K. Richardson, J. Rockström, S. E. Cornell, I. Fetzer, E. M. Bennett, R. Biggs, S. R. Carpenter, W. de Vries, C. A. de Wit, C. Folke, D. Gerten, J. Heinke, G. M. Mace, L. M. Persson, V. Ramanathan, B. Reyers, and S. Sörlin. 2015. Planetary boundaries: guiding human development on a changing planet. Science 347(6223):1259855. https://doi.org/10.1126/science.1259855

Stephens, L., D. Fuller, N. Boivin, T. Rick, N. Gauthier, A. Kay, B. Marwick, C. G. Armstrong, C. M. Barton, T. Denham, K. Douglass, J. Driver, L. Janz, P. Roberts, J. D. Rogers, H. Thakar, M. Altaweel, A. L. Johnson, M. M. S. Vattuone, M. Aldenderfer, S. Archila, G. Artioli, M. T. Bale, T. Beach, F. Borrell, T. Braje, P. I. Buckland, N. G. J. Cano, J. M. Capriles, A. D. Castillo, Ç. Çilingiroğlu, M. N. Cleary, J. Conolly, P. R. Coutros, R. A. Covey, M. Cremaschi, A. Crowther, L. Der, S. di Lernia, J. F. Doershuk, W. E. Doolittle, K. J. Edwards, J. M. Erlandson, D. Evans, A. Fairbairn, P. Faulkner, G. Feinman, R. Fernandes, S. M.
Fitzpatrick, R. Fyfe, E. Garcea, S. Goldstein, R. C. Goodman, J. D. Guedes, J. Herrmann, P. Hiscock, P. Hommel, K. A. Horsburgh, C. Hritz, J. W. Ives, A. Junno, J. G. Kahn, B. Kaufman, C. Kearns, T. R. Kidder, F. Lanoë, D. Lawrence, G.-A. Lee, M. J. Levin, H. B. Lindskoug, J. A. López-Sáez, S. Macrae, R. Marchant, J. M. Marston, S. McClure, M. D. McCoy, A. V. Miller, M. Morrison, G. M. Matuzeviciute, J. Müller, A. Nayak, S. Noerwidi, T. M. Peres, C. E. Peterson, L. Proctor, A. R. Randall, S. Renette, G. R. Schug, K. Ryzewski, R. Saini, V. Scheinsohn, P. Schmidt, P. Sebillaud, O. Seitsonen, I. A. Simpson, A. Sołtysiak, R. J. Speakman, R. N. Spengler, M. L. Steffen, M. J. Storozum, K. M. Strickland, J. Thompson, T. L. Thurston, S. Ulm, M. C. Ustunkaya, M. H. Welker, C. West, P. R. Williams, D. K. Wright, N. Wright, M. Zahir, A. Zerboni, E. Beaudoin, S. M. Garcia, J. Powell, A. Thornton, J. O. Kaplan, M.-J. Gaillard, K. K. Goldewijk, and E. Ellis. 2019. Archaeological assessment reveals Earth's early transformation through land use. Science 365 (6456):897-902. https://doi.org/10.1126/science.aax1192

Strumsky, D., J. Lobo, and J. A. Tainter. 2010. Complexity and the productivity of innovation. Systems Research and Behavioral Science 27(5):496-509. https://doi.org/10.1002/sres.1057

Tainter, J. A. 1988. The collapse of complex societies. Cambridge University Press, Cambridge, UK.

Tainter, J. A. 2006. Social complexity and sustainability. Ecological Complexity 3(2):91-103. https://doi.org/10.1016/j. ecocom.2005.07.004

Taleb, N. N., and C. Sandis. 2014. The skin in the game heuristic for protection against tail events. Review of Behavioral Economics 1(1-2):115-135. https://doi.org/10.1561/105.00000006

Tanimoto, M. 2006. The role of tradition in Japan's industrialization: another path to industrialization. Oxford University Press, Oxford, UK. https://doi.org/10.1093/0198292740.003.0001

Todd, P. M., and G. Gigerenzer. 2012. Ecological rationality: ontelligence in the world. Oxford University Press, Oxford, UK. https://doi.org/10.1093/acprof:oso/9780195315448.001.0001

Toivanen, T., K. Lummaa, A. Majava, P. Järvensivu, V. Lähde, T. Vaden, and J. T. Eronen. 2017. The many Anthropocenes: a transdisciplinary challenge for the Anthropocene research. Anthropocene Review 4:183-198. https://doi.org/10.1177/2053019617738099

van Schaik, C. P., and J. M. Burkart. 2011. Social learning and evolution: the cultural intelligence hypothesis. Philosophical Transactions of the Royal Society B: Biological Sciences 366 (1567):1008-1016. https://doi.org/10.1098/rstb.2010.0304

Watson, J. 2019. Lo-Tek: design by radical indigenism. Taschen. Cologne, Germany.

Weick, K. E. 1995. Sensemaking in organizations. Sage, Thousand Oaks, California, USA.

Weinstein, M. P., R. C. Baird, D. O. Conover, M. Gross, J. Keulartz, D. K. Loomis, Z. Naveh, S. B. Peterson, D. J. Reed, E. Roe, R. L. Swanson, J. A. A. Swart, J. M. Teal, R. E. Turner, and H. J. van der Windt. 2007. Managing coastal resources in the 21st century. Frontiers in Ecology and the Environment 5(1):43-48. https://doi.org/10.1890/1540-9295(2007)5[43:mcrits]2.0.co;2 
Williams, J. W., and S. T. Jackson. 2007. Novel climates, no-analog communities, and ecological surprises. Frontiers in Ecology and the Environment 5:475-482. https://doi.org/10.1890/070037

Wilson, D. S. 2020. This view of life: completing the Darwinian revolution. Vintage, New York, New York, USA.

Woolf, G. 2020. The life and death of ancient cities: a natural history. Oxford University Press, Oxford, UK.

Yang, L.-N., Z.-C. Pan, W. Zhu, E.-J. Wu, D.-C. He, X. Yuan, Y.Y. Qin, Y. Wang, R.-S. Chen, P. H. Thrall, J. J. Burdon, L.-P. Shang, Q.-J. Sui, and J. Zhan. 2019. Enhanced agricultural sustainability through within-species diversification. Nature Sustainability 2(1):46-52. https://doi.org/10.1038/s41893-018-0201-2

Yuan, F. L., U. P. Ballullaya, R. Roshnath, T. C. Bonebrake, and P. A. Sinu. 2020. Sacred groves and serpent-gods moderate human-snake relations. People and Nature 2(1):111-122. https:// doi.org/10.1002/pan3.10059

Zeder, M. A. 2012. The broad spectrum revolution at 40: resource diversity, intensification, and an alternative to optimal foraging explanations. Journal of Anthropological Archaeology 31 (3):241-264. https://doi.org/10.1016/j.jaa.2012.03.003 